Article

\title{
Exploratory Experimental Study on the Mechanical Properties of Granite Subjected to Cyclic Temperature and Uniaxial Stress
}

\author{
Guokai Zhao, Yaoqing Hu * and Peihua Jin \\ Key Laboratory of In-Situ Property Improving Mining of Ministry of Education, Taiyuan University of \\ Technology, Taiyuan 030024, China; fy1142406117@foxmail.com (G.Z.); jinpeihua0119@link.tyut.edu.cn (P.J.) \\ * Correspondence: huyaoqing@tyut.edu.cn
}

Received: 3 February 2020; Accepted: 13 April 2020; Published: 20 April 2020

check for updates

\begin{abstract}
This paper investigates the variation of mechanical properties of granite during temperature and stress cycling, which is an important part of evaluating the long-term thermal and mechanical stability of thermal energy storage. Cyclic temperature and loading tests were conducted where the upper limit of cyclic temperature was $100-600{ }^{\circ} \mathrm{C}$, and the upper stress limits were $70 \%$ and $85 \%$ of the average uniaxial compressive strength (UCS) at the corresponding temperature. The response of stress-strain characteristics of the granite samples to changes in temperature, and cyclic load upper limit, while the number of temperature and loading cycles was comprehensively analyzed. The results show that the temperature and stress cycles have significant effects on the mechanical properties of granite (i.e., stress-strain curve, strength, elastic modulus, and deformation). The elastic modulus of the sample during loading increases gradually. The strain corresponding to the upper loads of the granite samples decreases with an increasing number of cycles. Additionally, the UCS of samples after 10 cycles at $70 \%$ loading stress is greater than that at $85 \%$ loading stress. The mechanical properties of samples change dramatically during the first and second cycles at $85 \%$ loading stress, whereas at $70 \%$ loading stress, the mechanical properties change gradually in the first few cycles, and then tend to stabilize. Cyclic hardening is observed at temperatures below $500^{\circ} \mathrm{C}$, where post cyclic UCS is greater than the uncycled average UCS. This phenomenon requires further research.
\end{abstract}

Keywords: granite; cyclic temperature; cyclic stress; mechanical properties; energy dissipation

\section{Introduction}

A deep understanding of the effects of cyclic temperature and cyclic loading on the mechanical properties of rocks is critical for many high-temperature underground engineering applications, such as thermal energy storage (TES) [1,2], enhanced geothermal systems (EGS) [3-5] and compressed air energy storage (CAES) [6]. TES is a storage technology that is used in concentrated solar power plants [2]. It is an effective means to tackle the intermittency problem of renewable energy by storing excessive heat and releasing it later when needed. It is critical to consider the rock bed subjected to cyclic temperature [7-9]. Moreover, the periodic temperature stress due to cyclic temperature in a constrained environment acts simultaneously on the rock mass of TES [10]. As is known, granite is potentially suitable for TES [1]. Therefore, it is of considerable importance to understand the mechanical properties of granite subjected to cyclic temperature and cyclic loading, which is also associated with the long-term stability of TES systems.

Many earlier studies focused on the mechanical properties of rock subjected to either cyclic temperature or cyclic loading, but not both. In recent years, a concern regarding the effect of cyclic temperature on deep rock engineering and geotechnical engineering has arisen [11-22]. Some studies 
reported the effect of cyclic temperature on the physical and mechanical properties of rocks. Rong et al. [11,12] investigated the influence of thermal cycling on the physical and mechanical properties of rock (i.e., marble and granite) through a uniaxial compression test and conducted microscopic observations to investigate the thermal damage of rock sample induced by the treatment of different thermal cycles. Battaglia et al. [15] measured the linear thermal expansion of marbles subjected to thermal cycles utilizing a high-sensitivity apparatus. Lin et al. [16] investigated the variation of residual strain and micro-crack density of granite with cyclic temperature in the range of $600{ }^{\circ} \mathrm{C}$, and explained the mechanism of permanent deformation caused by micro-cracks from the microscopic perspective. Fang [18] analyzed and compared the effects of mechanical properties of marble subjected to thermal treatment and thermal cycling. They showed that the physical and mechanical properties of rock samples deteriorate gradually with an increasing number of temperature cycles. Further, other researchers considered that the deterioration of the mechanical properties of building materials and engineering structures in cold regions with harsh climatic conditions was due to freeze-thaw cycles [19-21].

Most of the earlier studies on the effect of cyclic loading on the mechanical properties of rocks did not consider the effect of temperature, i.e., the studies were carried out at room temperature. Momeni et al. [23] focused on the fatigue behavior under different maximum loads, frequencies, and amplitudes to infer the fatigue damage process of granitic rock. Ge et al. [24,25] conducted a systematic experimental study on the fatigue failure deformation and mechanism of various rock samples under uniaxial compression. They proposed that rock deformation may be the control standard and the threshold of fatigue failure of rock. Li et al. [26] studied the fatigue properties of cracked, saturated, and frozen sandstone under cyclic loading. Fan et al. [27-30] studied the fatigue properties of salt and concrete under discontinuous cyclic loading. Chen et al. [31] reported the patterns of micro-cracks at three characteristic stages by the digital image analysis technique after cyclic loading. Based on energy dissipation, Liu et al. [32] developed a damage constitutive model for two typical rocks subjected to cyclic loading. Li et al. [33] developed a damage model for fractured rock subjected to cyclic loading. He et al. [34] investigated the fatigue damage of salt rock and developed a fatigue life and damage model for salt rock. Xiao et al. $[35,36]$ reported a suitable damage variable to describe fatigue damage in granite subjected to cyclic loading. They suggested an inverted S-shaped nonlinear fatigue damage cumulative model.

Few studies considered the effects of cyclic temperature and stress on the mechanical properties of rock samples. Zhou et al. [6] investigated the effects of cyclic uniaxial stress-temperature on the fatigue properties of basalt, with a maximum temperature of $90^{\circ} \mathrm{C}$. However, the temperature corresponding to TES or EGS is much higher than $90^{\circ} \mathrm{C}$. In view of the engineering problems of rock under extremely complicated geological conditions, e.g., TES and EGS, cyclic temperature and loading tests were conducted in this study. The upper limit of cyclic temperature was $100^{\circ} \mathrm{C}$ to $600{ }^{\circ} \mathrm{C}$ and the upper stress limits were $70 \%$ and $85 \%$ of the UCS. Further, the influences of cyclic temperature and cyclic stress on the mechanical properties such as the stress-strain curves, rock strength, elastic modulus, deformation characteristic and energy dissipation were examined and discussed. The results of this study can be used as a reference for the safety and stability of TES and future studies on the fatigue failure of granite subjected to cyclic temperature and stress.

\section{Materials and Methods}

\subsection{Description of Granite Samples}

The rock material used in this study is granite, with no visible flaws, collected from Zhumadian City, Henan Province in China. Figure la shows a naked eye observation photograph of the granite sample. The granite is a weakly altered granodiorite with a light gray color. It is a semi-self-shaped medium-grained granular structure, and the mineral particle size is about $2-5 \mathrm{~mm}$. A total of 36 granite samples were prepared for mechanical properties testing. Thin sections were prepared and studied by 
polarized light microscopy to identify the dominant minerals. Figure $1 \mathrm{~b}$ is a thin section micrograph (crossed pollars) showing the microstructure and mineralogical composition of the sample. The analysis showed that the granite mainly comprises quartz, feldspar, plagioclase and biotite (Table 1). The rock sample cores of $60 \mathrm{~mm}$ length and $30 \mathrm{~mm}$ diameter were drilled from the same block, in the same direction to allow results to be comparable even with the existence of a mild anisotropy fabric, and the non-parallelism of the end faces of the samples was less than $0.02 \mathrm{~mm}$, which is in accordance with the ISRM suggested method [37]. In order to minimize the differences in the test results caused by the individual differences in the rock samples, the P-wave velocities of the samples were measured prior to each test using an NM-48 non-metallic ultrasonic detector. The samples with large differences in the P-wave velocity were rejected, and the samples with small differences in the P-wave velocity $(4.347-4.515 \mathrm{~km} / \mathrm{s})$ were selected for the mechanical tests.

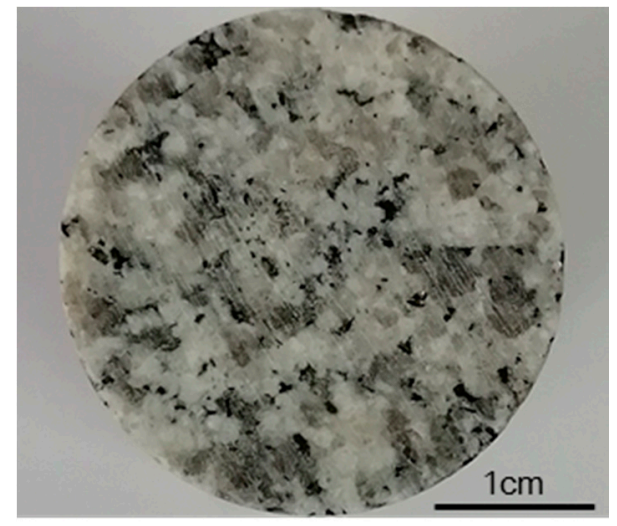

(a)



(b)

Figure 1. Observations of the granite at different scales: (a) naked eye observation and (b) a thin section micrograph showing the main mineralogical composition of the rock.

Table 1. Main mineral contents of granite.

\begin{tabular}{cccc}
\hline Quartz & Potassium Feldspar & Plagioclase & Biotite \\
\hline $20-25 \%$ & $40-45 \%$ & $30-35 \%$ & $3-5 \%$ \\
\hline
\end{tabular}

\subsection{Experimental Procedure}

In this study, the uniaxial stress-strain tests of granite subjected to cyclic temperature and loading were performed utilizing a multi-functional rock high temperature triaxial testing machine, as shown in Figure 2. The testing machine mainly comprises an electro-hydraulic servo control loading system, a temperature control system, a high-stiffness rock triaxial system, as well as a computer measurement and control system. The machine is mainly used for measuring the high temperature mechanical and transport properties of rock samples. It uses the servo control to apply a load on the sample. The maximum axial force of the test machine is $1000 \mathrm{kN}$ and the maximum heating temperature is $650{ }^{\circ} \mathrm{C}$. During the test, the axial stress and the sample deformation were measured by the pressure sensor and the axial displacement sensor, respectively. The sensor signal was automatically recorded by the computer through the digital acquisition module. The strain was calculated from an axial displacement sensor distant from the sample divided by the sample dimension of $60 \mathrm{~mm}$. Thus, the modulus may differ from that calculated using a strain gauge approach but it is the only practical approach in this complex test situation.

Under the current test technology, it is difficult to ensure that the heating and cooling of the rock samples are synchronized with the stress loading and unloading. Therefore, it is impossible to guarantee that the processes of heating-cooling and loading-unloading in the test are in full correspondence with the engineering practice that involves temperature change and alternate loading in deep underground 
engineering. This is also the difficulty of the multi-field coupling fatigue problem under extremely complex geological conditions, which needs to be solved in deep rock mass mechanical engineering. Therefore, this simplified model of heating-loading-unloading-cooling was used in this study as a complete cycle of temperature and stress [6]. In order to investigate the influence of cycling temperature on the mechanical properties of granite, the six temperature points of $100{ }^{\circ} \mathrm{C}, 200^{\circ} \mathrm{C}, 300{ }^{\circ} \mathrm{C}, 400{ }^{\circ} \mathrm{C}$, $500{ }^{\circ} \mathrm{C}$, and $600{ }^{\circ} \mathrm{C}$ were used in the test. To investigate the influence of cycling loading on the mechanical properties of granite, two sets of stress levels were applied on the samples, i.e., $70 \%$ or $85 \%$ of the UCS of the samples subjected to different temperatures. The mechanical properties of the same rock at high constant temperature tests were investigated elsewhere [38] and the average UCS at each temperature is shown in Table 2. In the investigation of the mechanical properties of granite subjected to temperature and stress cycles, the upper stress limits were $70 \%$ and $85 \%$ of the average UCS at each temperature, which may be slightly different from the testing cyclic stress of the samples because of the differences in the test results caused by individual differences in the rock samples. Therefore, in this experiment, the upper limit of stress should be about $70 \%$ and $85 \%$ of its average UCS, which results in a different fatigue life for different samples at the same temperature. However, the evolution of mechanical properties of the samples is the same, i.e., this study only reveals the variation trend.

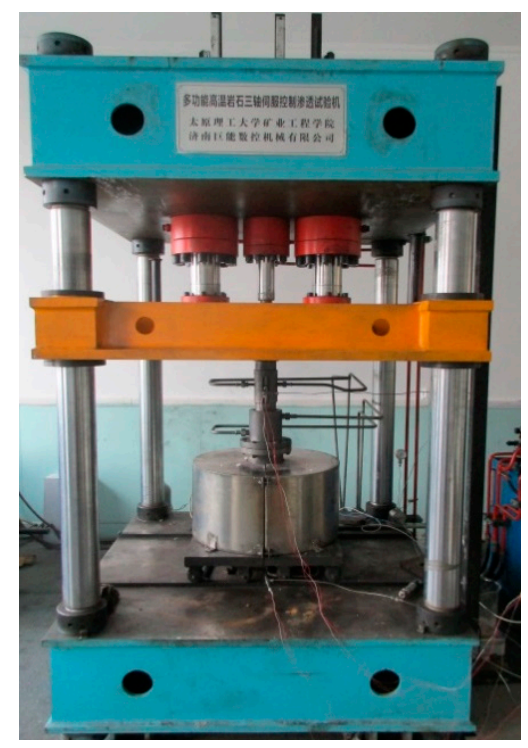

Figure 2. Multi-Functional rock high temperature triaxial testing machine.

The temperature and stress cycles were as follows. After installing the sample in the designated position of the testing machine, the temperature control system was used to raise the temperature to the upper limit cyclic temperature at a rate of $2{ }^{\circ} \mathrm{C} / \mathrm{min}$ and then held for $2 \mathrm{~h}$ so that the sample was heated evenly. The sample was then compressed uniaxially to $70 \%$ and $85 \%$ of the average UCS at each temperature at a rate of $0.1 \mathrm{kN} / \mathrm{s}$ and then the loading was decreased to zero at a rate of $0.1 \mathrm{kN} / \mathrm{s}$. The computer measurement and control system automatically collected and recorded the axial force and the deformation of the sample during this loading-unloading cycle. Finally, the heating furnace was turned off and the sample was left in the furnace to slowly cool down to the room temperature of $25{ }^{\circ} \mathrm{C}$. Thus, the temperature range for a cycle was between the upper limit cyclic temperature and the room temperature. For each upper limit cyclic temperature, the temperature and stress cycles were repeated nine times. However, the cycle was sometimes repeated less than nine times. If a sample broke during the cycle, the test was terminated. Otherwise, the final uniaxial compression test of the sample was performed after the 10th temperature reached the set value and was held for $2 \mathrm{~h}$.

This test takes a long time to complete. It takes about $9 \mathrm{~h}$ to carry out one temperature and stress cycle test and it takes about $86 \mathrm{~h}$ to complete all the cycles for one sample. As such, instead of carrying 
out the full experiment, an exploratory study was carried out. The number of temperature and stress cycles in this exploratory study was set to 10 . The purpose was to explore the effects of simultaneous cyclic temperature and stress on the mechanical properties of the granite sample and provide some references for future studies on the fatigue damage of granite subjected to cyclic temperature and stress.

Table 2. Average mechanical parameters of Zhumadian granite at high temperature [38]. Reproduced from [38], Springer Nature 2020.

\begin{tabular}{cccc}
\hline Temperature $/{ }^{\circ} \mathbf{C}$ & Uniaxial Compressive Strength/MPa & Elastic Modulus/GPa & Peak Strain \\
\hline 100 & 129.54 & 12.59 & 0.01254 \\
200 & 110.21 & 10.89 & 0.01223 \\
300 & 114.10 & 9.95 & 0.01386 \\
400 & 116.52 & 10.11 & 0.01356 \\
500 & 105.19 & 9.39 & 0.01259 \\
600 & 105.12 & 9.20 & 0.01412 \\
\hline
\end{tabular}

\section{Results and Analyses}

\subsection{Stress-Strain Curve}

Figures 3 and 4 show the stress-strain curves of the granite samples subjected to cyclic temperature and stress. The upper limit of cyclic temperature is $100{ }^{\circ} \mathrm{C}$ to $600{ }^{\circ} \mathrm{C}$, and the upper stress limits are $70 \%$ and $85 \%$ of the UCS at the corresponding temperature. Since the stress-strain curves during loading and unloading are very close to each other, it is difficult to see the trend of the stress-strain curves of the samples during the 10 temperature and stress cycles. Therefore, Figures 3 and 4 only show the stress-strain curves of the first, second, third, fifth, ninth, and the final tenth cycles. Only minor differences can be seen among the stress-strain curves as the curves are almost coincident.

From Figure 3, it can be seen that during the temperature and stress cycle, when the upper limit of cyclic temperature is $100{ }^{\circ} \mathrm{C}$ to $400{ }^{\circ} \mathrm{C}$, the stress-strain curves of the samples gradually shift to the left during the first few cycles. As the number of cycles increases, the stress-strain curves become closer to each other. When the upper limits of cyclic temperatures are $500^{\circ} \mathrm{C}$ and $600{ }^{\circ} \mathrm{C}$, the stress-strain curves are close to each other.
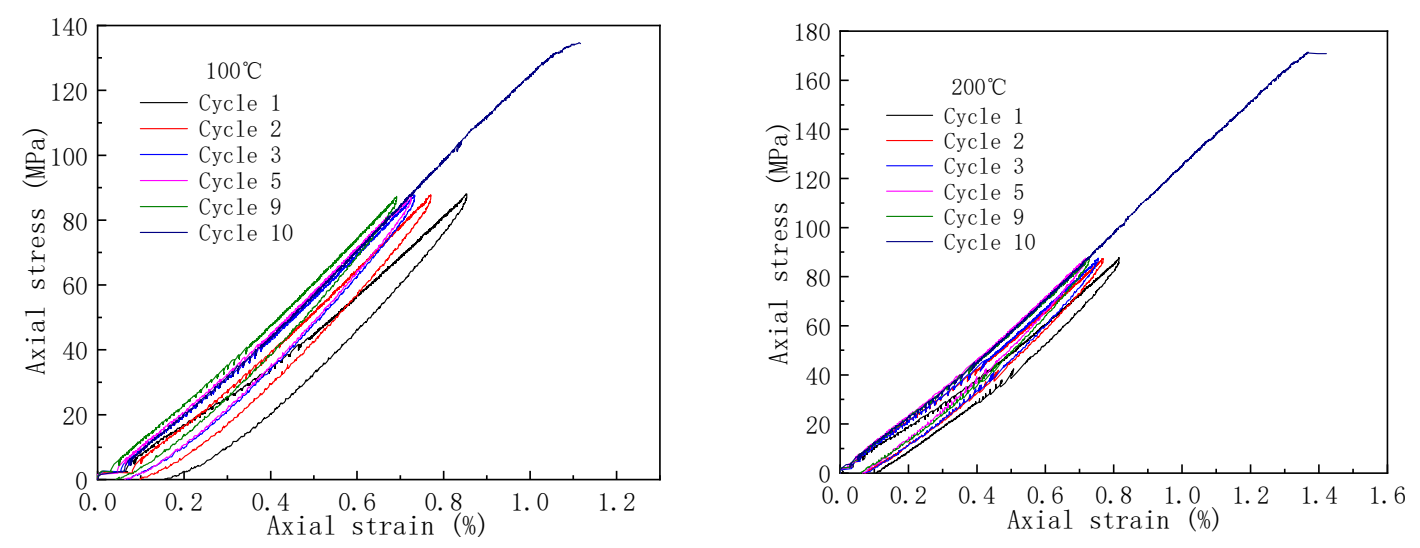

Figure 3. Cont. 

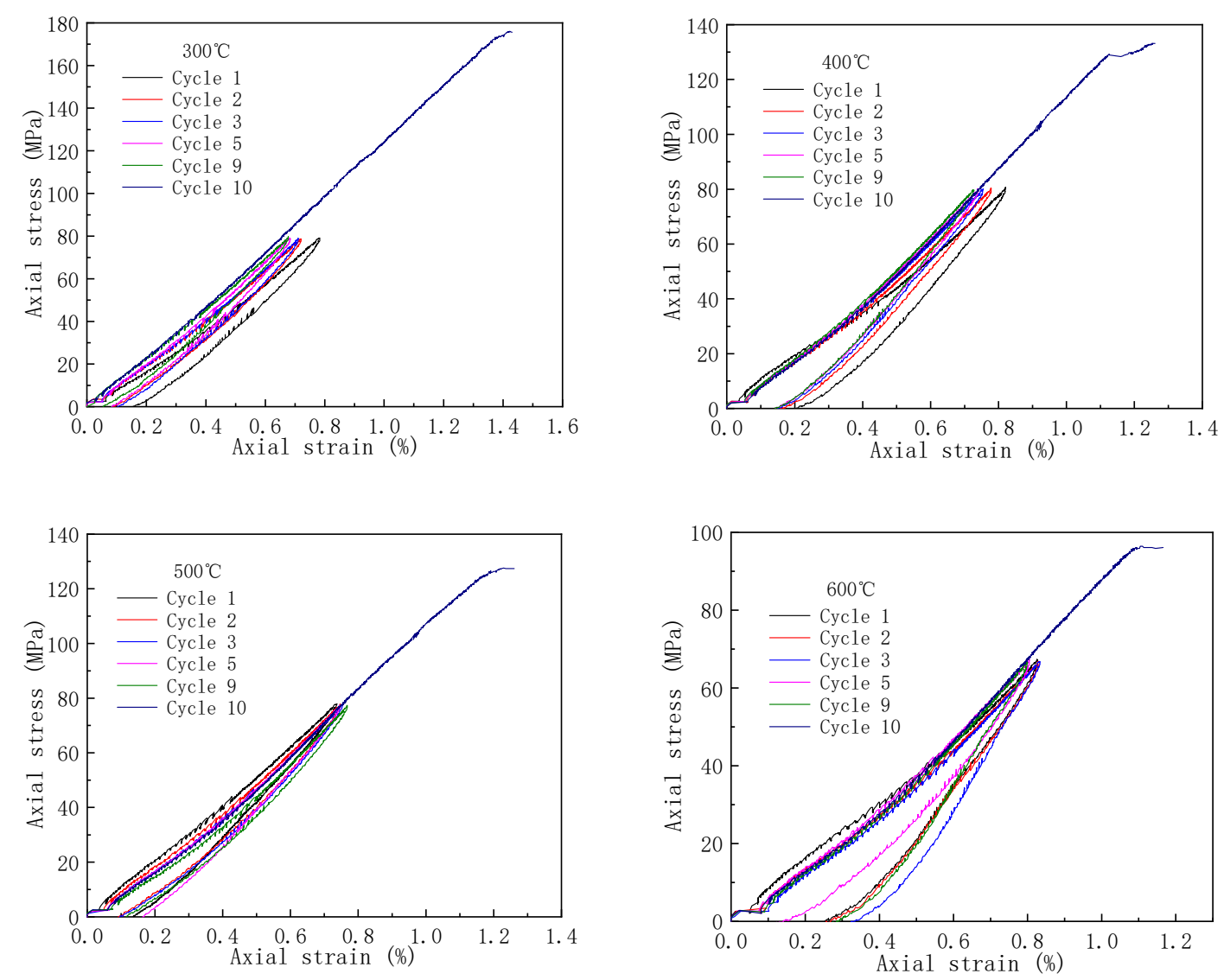

Figure 3. Stress-strain curves of granite sample when the upper limit of cyclic stress is 70\% of UCS at six upper limit cyclic temperatures.

In Figure 4, it can be seen that the stress-strain curves for different cycles do not coincide, and the hysteresis loops of the stress-strain curves are not closed. The area of the hysteresis loop formed by the first loading-unloading cycle is much larger compared to the hysteresis loops formed by the subsequent loading-unloading cycles. In this study, the area of the hysteresis loop represents the dissipated energy. As can be seen from the stress-strain curves, except for the first loading-unloading curve, other loading-unloading curves are slightly different. When the upper limit of cyclic temperature is $100{ }^{\circ} \mathrm{C}$ to $500^{\circ} \mathrm{C}$, the stress-strain curves of the granite samples gradually shift to the left as the number of cycles increases, i.e., the strain gradually decreases and the elastic modulus gradually increases under this stress condition. This is an indication that the plastic deformation is relatively large during the first cycle and then becomes smaller as the number of cycles increases. When the upper limit of cyclic temperature is $600{ }^{\circ} \mathrm{C}$, the stress-strain curves of the granite samples shift to the left as the cycles proceed. However, the granite sample fails prior to the loading of the upper limit of the cyclic stress in the fifth cycle. In fact, the other two samples fail in the second and third cycle, respectively. For these three samples, the loading curve of this cycle shifts to the right from the previous cycle, i.e., the elastic modulus decreases. Further, the sample exhibits obvious hardening characteristics as the cycles continue. Finally, the sample fails by fatigue. This is mainly because quartz changes from $\alpha$ phase to $\beta$ phase at around $573^{\circ} \mathrm{C}$ [39]. The volume of the sample increases as quartz changes phase, and the micro-cracks increase significantly. In this study, the mineral content of quartz in the granite sample is relatively high. When it is subjected to temperature and stress cycles, the loading and unloading curves gradually shift to the left. However, in the last cycle before the failure, the curves suddenly shift to the right, which is an indication that the mechanical properties of the granite sample have deteriorated. Thereafter, the sample fails. 



Figure 4. Stress-strain curves of granite sample when the upper limit of cyclic stress is $85 \%$ of UCS at six upper limit cyclic temperatures.

Another noteworthy phenomenon is that as the maximum stress level increases, the stress-strain curve of the granite changes during the cycle. For the tests at $70 \%$ UCS with temperature up to $400{ }^{\circ} \mathrm{C}$, the stress-strain curves of the granite samples are not close to each other during the initial stage. They gradually become close to each other as the cycles continue. When the upper limit of cyclic temperature is $500{ }^{\circ} \mathrm{C}$ to $600{ }^{\circ} \mathrm{C}$, the stress-strain curves are close to each other. For the tests at $85 \%$ UCS with temperature up to $600{ }^{\circ} \mathrm{C}$, except for the first loading and unloading curves, the subsequent loading and unloading curves are close to each other. Further, the area of the hysteresis loop formed by the first loading and unloading curves is larger than the loop areas formed by loading and unloading curves in the subsequent cycles. When the upper limit of cyclic temperature is $600^{\circ} \mathrm{C}$, the loading and 
unloading curves shift to the left as a whole, but the sample fails in the fifth cycle prior to the loading of the upper limit of the cyclic stress.

\subsection{Rock Strength and Elastic Modulus}

Figure 5 shows the UCS of granite samples at high temperature and after 10 cycles of temperature and stress. The upper limit of cyclic temperature is $100^{\circ} \mathrm{C}$ to $600{ }^{\circ} \mathrm{C}$, and the upper limits of cyclic stress are $70 \%$ and $85 \%$ of the UCS. After 10 cycles of temperature and stress, the UCS of the granite samples at $70 \%$ loading stress is greater than that at $85 \%$ loading stress and the variations of the UCS of the samples with temperature are approximately the same. That is, the UCS increases when the temperature is $100-300{ }^{\circ} \mathrm{C}$ and then generally decreases when the temperature is $300-600{ }^{\circ} \mathrm{C}$. Except for $600{ }^{\circ} \mathrm{C}$, the UCS of the samples after 10 cycles of temperature and stress is greater than that at high temperature. The UCS after 10 temperature and stress cycles is the largest when the upper limit cyclic temperature is $300{ }^{\circ} \mathrm{C}$. Further, the largest strength of the samples at $70 \%$ and $85 \%$ loading stress is respectively $53.9 \%$ and $50.9 \%$ higher than that at high temperature.

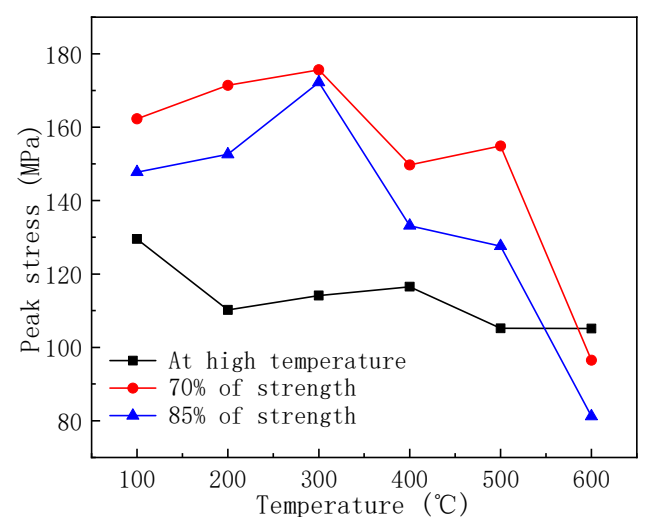

Figure 5. Comparison of UCS of samples at high temperature and after exposure to 10 cycles of temperature and stress.

For the test at $85 \%$ UCS with temperature of $600{ }^{\circ} \mathrm{C}$, the samples fail in the fifth cycle. When the upper stress limit is $70 \%$ of the UCS, the samples do not fail within the nine cycles, but the UCS of the samples after 10 cycles is lower than that at high temperature. Therefore, under the experimental conditions of this study, there is a temperature threshold between $500^{\circ} \mathrm{C}$ and $600{ }^{\circ} \mathrm{C}$. When the cycle temperature is lower than the threshold temperature, not only does the sample not fail by fatigue during the nine temperature and stress cycles, but the UCS after 10 temperature and stress cycles is also greater than that at high temperature. When the cycle temperature is higher than the threshold temperature, the fatigue damage of the samples is intensified. After the 10 temperature and stress cycles, the UCS of the samples is lower to different degrees than that at high temperature. Further, the sample fails by fatigue during the cyclic process when the upper stress limit is $85 \%$ of the UCS. However, the sample does not fail when the upper stress limit is $70 \%$ of the UCS. These results show that the failure of the granite samples is not only related to the cycle temperature but also to the upper limit of stress.

The elastic modulus of rock describes its resistance to deformation and determines the stiffness of the rock structure. Figure 6 shows the change in the elastic modulus during the loading phase of the temperature and stress cycle, where the upper limit of cyclic temperature is $100{ }^{\circ} \mathrm{C}$ to $600{ }^{\circ} \mathrm{C}$, and the upper limits of stress are $70 \%$ and $85 \%$ of the UCS. In this study, the elastic modulus refers to the slope of the line determined from the linear portion of the stress-strain curve between $40 \%$ and $60 \%$ of the peak stress.

Several researchers $[24,40]$ have reported that the fatigue failure of rock at room temperature consists of three stages, i.e., Stage I, the initiation stage in which fatigue cracks are formed; Stage II, the 
uniform velocity stage in which there is stable growth of cracks, and Stage III, the accelerated stage in which there is unstable growth of cracks resulting in a sudden failure. Figure 6 shows the variations of the elastic modulus of the samples subjected to cyclic temperature and stress with the number of cycles. This result is consistent with that of Zhou et al. [6] who determined the elastic modulus of hardened basalt rock sample in the first 10 temperature and stress cycles. Under the experimental conditions of this study, during temperature and stress cycles, the variations of the elastic modulus of the granite samples with the number of cycles consist of two phases. The elastic modulus of the granite samples at $70 \%$ loading stress increases significantly followed by increases gently, whereas for the samples at $85 \%$ loading stress, the elastic modulus increases suddenly then is more or less constant.


Figure 6. Variations of elastic modulus of granite samples with number of temperature and stress cycles at six upper limit cyclic temperatures (a) upper limit of cyclic stress $=70 \%$ of UCS, (b) upper limit of cyclic stress $=85 \%$ of UCS.

Figure 7 shows the variations of the difference in elastic modulus $(\Delta E)$, which is the difference between the elastic modulus of the tenth loading $\left(E_{10}\right)$ and that of the first loading $\left(E_{1}\right)$, with cyclic temperature. The elastic modulus of the tenth loading is larger than that of the first loading after 10 temperature and stress cycles, and the increase amplitudes of the elastic modulus are different at different cycle temperatures. For the tests at $70 \%$ UCS with temperature up to $400{ }^{\circ} \mathrm{C}$, the difference in elastic modulus only varies slightly with temperature. When the upper stress limit is $85 \%$ of the UCS, the difference in elastic modulus increases gradually with increasing temperature, and reaches a maximum at $400{ }^{\circ} \mathrm{C}$. This result indicates that the loading stress has a great influence on the elastic modulus of the sample. A larger the loading stress (e.g., $85 \%$ of the UCS) increases the compactness of the sample, resulting in a larger elastic modulus at a higher temperature. However, when the upper limit of cyclic temperature is $500-600{ }^{\circ} \mathrm{C}$, the difference in elastic modulus decreases with increasing temperature for both loading stress (i.e., $75 \%$ and $85 \%$ of the UCS). This indicates that the thermal fracture caused by the cyclic temperature leads to an increase in internal defects, which may include the destruction of mineral lattice framework. Hence, the resistance of the samples to deformation gradually decreases and they go from ductile to brittle, resulting in a decrease in the difference in elastic modulus at higher cycle temperature.

In addition, from Figure 7, it can be seen that the difference in elastic modulus of the granite samples at upper stress limit of $85 \%$ of the UCS is larger than that at upper stress limit of $70 \%$ of the UCS, except for $100{ }^{\circ} \mathrm{C}$. This indicates that the elastic capacity of the samples subjected to cyclic temperature and stress when the upper limit of stress is $85 \%$ of the UCS is larger than that when the upper stress limit is $70 \%$ of the UCS. So, for granite subjected to temperature and stress cycles, higher cyclic stress makes the granite more elastic. However, it is not clear yet what kind of cyclic stress results in the maximum elasticity of granite under cyclic temperature and stress. Hence, other stress levels need to be tested in future studies. 


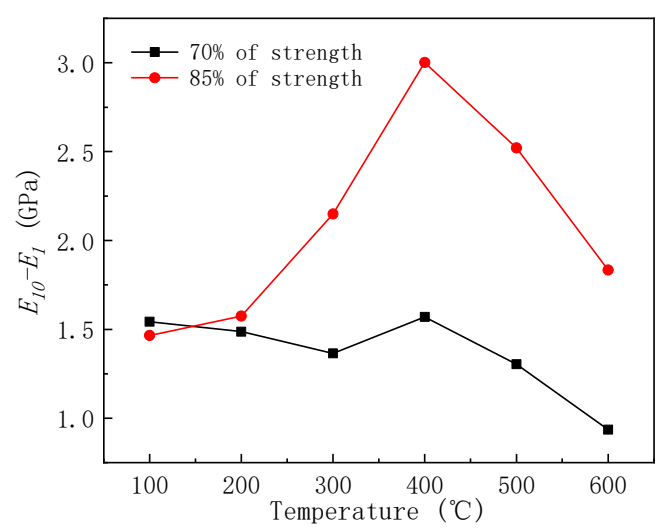

Figure 7. Difference in elastic modulus between the first loading $\left(E_{1}\right)$ and the tenth loading $\left(E_{10}\right)$ versus temperature.

\subsection{Deformation Characteristics}

One of the main purposes of investigating the deformation characteristics of rocks subjected to cyclic temperature and cyclic loading is to determine the evolution of rock damage with number of cycles. According to the results of earlier studies on the fatigue characteristics of rocks [24,40], there are three stages in the deformation development of rocks under cyclic loading. Further, the changes in the loading rate, loading path, upper and lower limits of stress loading, and stress amplitude affect the process of fatigue failure (i.e., fatigue life). However, these changes only affect the ultimate deformation of the rock during fatigue failure slightly and deformation may be the real standard of rock fatigue failure [24]. To study the fatigue deformation characteristics and evolution of a rock mass subjected to cyclic loading can help to understand the fatigue mechanism of the rock mass and scientifically evaluate the long-term stability of the rock mass. The ultimate deformation trend of rock fatigue failure is of great importance both in theory and in engineering practice. Thus, in this study, the fatigue failure and the strength of rock were investigated from the perspective of deformation.

Figure 8 shows the variations of the strain corresponding to the upper loads (i.e., $70 \%$ and $85 \%$ of the average UCS) with increasing number of cycles. The strain corresponding to upper loads of granite samples subjected to cyclic temperature and cyclic stress decreases with increasing number of cycles. When the upper stress limit is $70 \%$ of the UCS (Figure $8 \mathrm{a}$ ), shows the variations of the strain corresponding to the upper loads with the number of cycles are relatively flat and it does not change significantly during the first two cycles. When the upper stress limit is $85 \%$ of the UCS, Figure $8 b$ shows the strain corresponding to the upper loads decreases sharply during the first two cycles and then decreases gently and linearly during the subsequent cycles. This is because, after the temperature treatment, there are a large number of micro-cracks in the sample. After the first cyclic stress, most of these micro-cracks are closed, resulting in a large compression deformation. The subsequent strain corresponding to the upper loads decreases gently as the cycles continue because the micro-cracks of the sample are already closed and the ability of the samples to resist compression is enhanced. This indicates that the samples can be compacted quickly at $85 \%$ loading stress. 

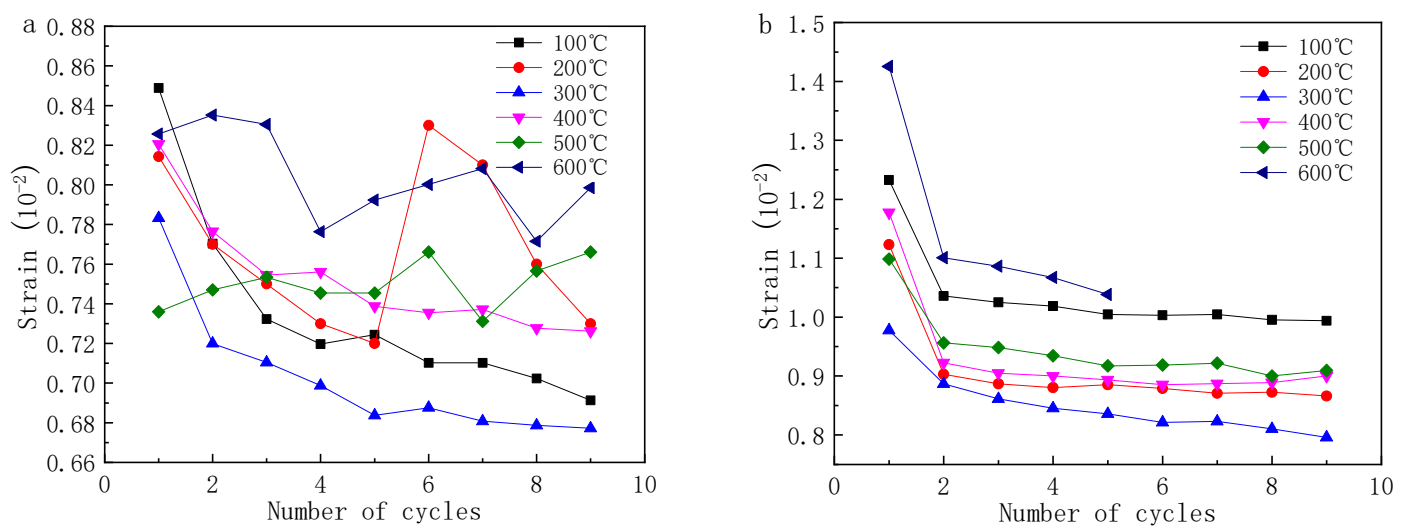

Figure 8. Variations of strain corresponding to upper loads of granite samples with number of temperature and stress cycles at six upper limit cyclic temperatures (a) upper limit of cyclic stress $=70 \%$ of UCS, (b) upper limit of cyclic stress $=85 \%$ of UCS.

\subsection{Dissipated Energy}

Energy dissipation is an essential attribute that reflects the continuous closure of micro-defects in a rock and the initiation and propagation of new cracks, as well as the friction and slip of existing crack surfaces [41,42]. The axial stress-strain curve of the fifth cycle of the granite sample is taken as an example, as shown in Figure 9. The upper limit of cyclic temperature is $500{ }^{\circ} \mathrm{C}$ and the upper stress limit is $85 \%$ of the UCS. It can be seen that the unloading curve does not coincide with the loading curve, and lags behind the loading curve. From the perspective of energy, during the loading process, part of the external force is transformed into releasable elastic strain energy through elastic deformation, and part of it is consumed in the form of thermal energy, acoustic emission energy, kinetic energy and plastic deformation $[43,44]$. The absorption energy is represented by the area enclosed by the loading curve and the coordinate axes. The elastic energy $\left(\mathrm{U}^{\mathrm{e}}\right)$ is given by the area surrounded by the unloading curve and the coordinate axes. Thus, the difference between the two, i.e., the area surrounded by the loading and unloading curve and the coordinate axes is the energy consumed during the loading-unloading process, namely the dissipation energy or hysteresis energy $\left(U^{d}\right)$ [23].

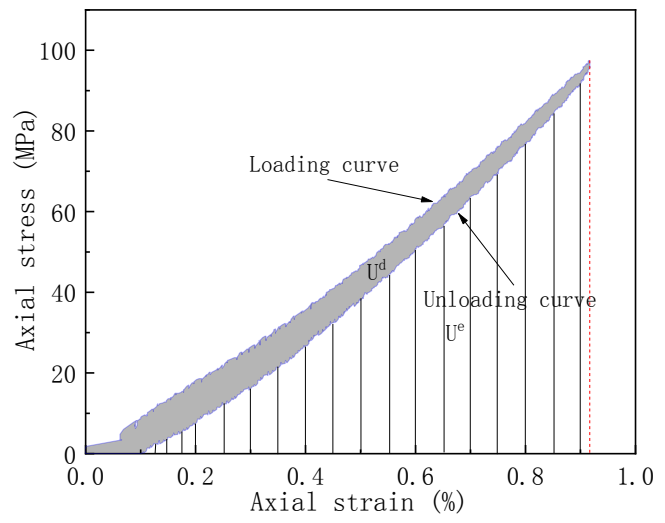

Figure 9. Distribution of elastic energy and dissipated energy of the fifth cycle at $500{ }^{\circ} \mathrm{C}$ cycle temperature.

Figures 10 and 11 show the variations of the absorption energy and the hysteresis energy of the granite samples with number of temperature and stress cycles. The upper limit of cyclic temperature is $100-600{ }^{\circ} \mathrm{C}$ and the upper stress limits are $70 \%$ and $85 \%$ of the UCS. From Figure 10, it can be seen that the energy absorbed by the rock samples during the loading process decreases generally with the increase in number of cycles, and then it gradually tends to stabilize. Further, the absorption energy of 
the rock samples at 70\% loading stress during the loading process reduces successively during the first few cycles and then tends to stabilize, whereas for the samples at $85 \%$ loading stress, there is a sharp decrease in the absorption energy during the first two cycles and then changes slightly. Figure 11 shows similar trends for the hysteresis energy when the upper limit of cyclic temperature is $100-500{ }^{\circ} \mathrm{C}$. The hysteresis energy decreases and increases with the number of cycles when the upper limit cyclic temperature is $600{ }^{\circ} \mathrm{C}$ and the upper stress limits are $70 \%$ and $85 \%$ of the UCS. When the upper stress limit is $85 \%$ of the UCS, the granite sample fails within nine cycles. When the upper stress limit is $70 \%$ of the UCS, the samples do not fail during nine cycles, but the UCS of the samples after the tenth temperature cycle is lower than that at high temperature.


Figure 10. Variations of absorption energy of granite samples with number of temperature and stress cycles at six upper limit cyclic temperatures (a) upper limit of cyclic stress $=70 \%$ of UCS, (b) upper limit of cyclic stress $=85 \%$ of UCS.
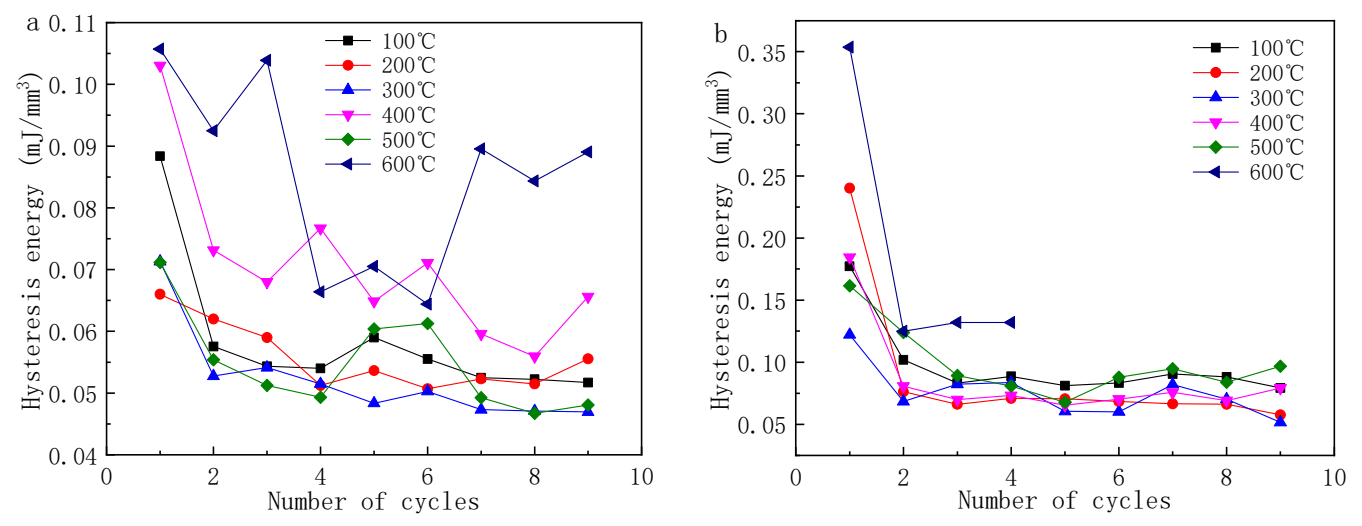

Figure 11. Variations of hysteresis energy with number of temperature and stress cycles at six upper limit cyclic temperatures (a) upper limit of cyclic stress $=70 \%$ of UCS, (b) upper limit of cyclic stress $=85 \%$ of UCS.

\section{Discussion}

Under the influence of temperature, thermal cracking occurs inside the granite due to the anisotropy and mismatch of the thermal expansion of the minerals, and the release of water inside the granite increases the amount of internal micro-cracks [45-47]. Therefore, the damage of the granite sample caused by the temperature increases with temperature. On the one hand, the stress from the subsequent cycles produces more micro-cracks. On the other hand, it promotes the closure of micro-cracks caused by temperature. However, the micro-cracks do not recover to their initial positions [48]. The plastic deformation of the structural surfaces of the micro-cracks consumes a certain amount of energy [48]. Figure 11 shows that the hysteresis energy decreases generally with the increasing number of cycles. This is because, during the first few temperature and stress cycles, the 
energy is mainly used for closing the micro-cracks caused by thermal cracking at high temperature, and for closing the original cracks and initiating new cracks in the granite samples. Therefore, during the first few cycles, the dissipation of energy is very large. The energy consumed in the subsequent cycles is mainly used for the damage to the granite samples caused by the temperature and stress cycle and the closing of the cracks. From the quantitative level of the hysteresis energy, the amount of micro-cracks generated by the temperature and stress cycles is less than that caused by thermal cracking at high temperature. Thus, the energy dissipated is smaller and then it gradually tends to stabilize. This is the reason why the hysteresis loops in Figures 3 and 4 become closer to each other with the increase in number of cycles. Moreover, this is also the reason why the mechanical properties (i.e., UCS and elastic modulus) of the samples increase to varying degrees when the upper limit of cyclic temperature is $100-500{ }^{\circ} \mathrm{C}$.

Further, it is well known that at a constant upper limit stress, as a rock sample hardens or softens due to the cyclic loading, the corresponding axial strain then decreases or increases, respectively. From Figure 8 , it can be seen that the strain corresponding to the upper loads decreases gradually. Moreover, the elastic modulus of the loading curve (in Figure 6) increases gradually with increasing number of cycles. This is a reflection of the cycle hardening effect in the macroscopic aspect. This strain hardening effect is also reflected in the complex evolution process of the micro-damage of the granite sample subjected to the cyclic temperature and cyclic stress.

Several studies have shown that strain hardening [38,49] and strain softening [50-54] phenomena are involved in the deformation of rock materials. According to the study of Ge $[24,25]$ and Wang et al. [40], for the upper loads lower than the fatigue threshold, the rock sample tends to harden when the rock is only subjected to cyclic loading. When the rock is subjected to cyclic temperature only, Rong et al. [11] and Fang [18] showed that the mechanical properties of the rock samples deteriorate gradually, and the higher the upper temperature limit, the more significant is the deterioration. Zhou et al. [6] compared the results of the study of a rock subjected to either cyclic temperature or cyclic loading with that of basalt under cyclic uniaxial stress and temperature. They preliminarily verified that the coupling of cyclic temperature and cyclic stress has a superposition effect on rock damage, as the effect of cyclic temperature exacerbates the damage of the rock under cyclic stress. In this study, the strain corresponding to the upper loads of the granite samples subjected to cyclic temperature and cyclic stress reduces gradually, which indicates the strain hardening of the granite samples caused by cyclic temperature and cyclic stress. Due to the combined action of cyclic temperature and stress, the internal micro-structure of the granite is adjusted. The external forces such as cyclic temperature or cyclic stress cause deformation of mineral particles inside the rock, changes in the arrangement of mineral particles (extrusion deformation dislocations) [29], and repeated opening and closing of the internal micro-cracks [48], resulting in the initiation and propagation of micro-cracks inside the rock. Irreversible plastic deformation occurs in the sample when it is subjected to temperature and stress cycling, and the strength of the deformed structure increases continuously, resulting in hardening of the sample.

The above results show the evolution of the mechanical properties and energy properties of granite samples subjected to cyclic temperature and cyclic stress, which are important for many high-temperature underground engineering applications, such as EGS and TES. Based on this study, the mechanical performance of bedrock under complex geological conditions can be understood. In addition, the results also present a cyclic hardening effect. When the upper limit of cyclic temperature is $100-500{ }^{\circ} \mathrm{C}$, the UCS of the samples after 10 cycles of temperature and stress is greater than that at high temperature. However, higher temperature may also be harmful to the strength of bedrock. When the upper limit of cyclic temperature is $600{ }^{\circ} \mathrm{C}$, the UCS of the samples after 10 cycles of temperature and stress is lower than that at high temperature. Further, when the upper stress limit is $85 \%$ of the UCS, the granite samples fail suddenly during the process of decreasing strain. This suggests that the performance of bedrocks during high-temperature geo-engineering should be re-examined. 
To investigate the evolution of the micro-structure of bedrock under complex geological conditions, high-precision X-ray computed tomography scanning will be conducted in future study.

\section{Conclusions}

This study experimentally investigates the effects of simultaneous cyclic temperature and cyclic loading on the mechanical properties of granite. The main conclusions are as follows.

(1) When the upper cycle stress limit is 70\% of the UCS and the upper limit of cyclic temperature is $100-400{ }^{\circ} \mathrm{C}$, the stress-strain curves of the samples gradually shift to the left during the first few cycles. As the number of cycles increases, the stress-strain curves become closer to each other. When the upper limit of cyclic temperature is $500-600{ }^{\circ} \mathrm{C}$, the stress-strain curves of the samples are very close to each other. When the upper cycle stress limit is $85 \%$ UCS and the upper limit of cyclic temperature is $100-600^{\circ} \mathrm{C}$, except for the first loading and unloading curve, the subsequent loading and unloading curves are close to each other. Further, the area of the hysteresis loop formed by the first loading and unloading curve is larger than those formed by the subsequent cycles.

(2) For six cycle temperatures, the UCS values of the granite samples after 10 temperature and stress cycles have approximately the same trends. Moreover, the UCS of the samples after 10 cycles at $70 \%$ loading stress is greater than that at $85 \%$ loading stress. Except for $600{ }^{\circ} \mathrm{C}$, the UCS of the samples subjected to 10 temperature and stress cycles is greater than that at high temperature.

(3) There is a temperature threshold between $500{ }^{\circ} \mathrm{C}$ and $600{ }^{\circ} \mathrm{C}$. When the cycle temperature is lower than the threshold temperature, not only does the sample not fail by fatigue during the 10 temperature and stress cycles, but also the UCS after 10 cycles is greater than that at high temperature. When the cycle temperature is higher than the threshold temperature, the fatigue damage of the samples is intensified. After 10 cycles, the UCS of the samples is lower to different degrees than that at high temperature.

(4) As the cycles continue during the 10 cycles, the elastic modulus of the sample during loading increases gradually. Further, the elastic modulus of the tenth loading is larger than that of the first loading. The increase in amplitude of the elastic modulus is different at different temperatures.

(5) The strain corresponding to the upper loads of the granite samples decreases with increasing number of cycles. The variation of the strain corresponding to the upper loads with the number of cycles is relatively flat and it does not change significantly during the first two cycles at $70 \%$ loading stress. The strain corresponding to the upper loads decreases sharply during the first two cycles and then decreases gently and linearly during the subsequent cycles when the upper stress limit is $85 \%$ of the UCS.

(6) The absorption energy of the rock samples at 70\% loading stress during the loading process reduces successively during the first few cycles and then tends to stabilize, whereas at $85 \%$ loading stress, there is a sharp decrease in the absorption energy during the first two cycles and then it changes slightly. Similar trends are observed for the hysteresis energy when the upper limit of cyclic temperature is $100-500{ }^{\circ} \mathrm{C}$. The hysteresis energy decreases and increases with the number of cycles when the upper limit of cyclic temperature is $600{ }^{\circ} \mathrm{C}$ and the upper stress limits are $70 \%$ and $85 \%$ of the UCS.

Author Contributions: All authors contributed to the research in the paper. G.Z. and Y.H. conceived and designed the experiments. The manuscript was then prepared by G.Z. and revised by P.J. All authors have read and agreed to the published version of the manuscript.

Funding: This work was funded by the National Natural Science Foundation of China (Grants No. 51574173).

Conflicts of Interest: The authors declare that they have no conflict of interest. 


\section{References}

1. Allen, K.; Von Backström, T.; Kröger, D.; Kisters, A.; Von Backström, T. Rock bed storage for solar thermal power plants: Rock characteristics, suitability, and availability. Sol. Energy Mater. Sol. Cells 2014, 126, 170-183. [CrossRef]

2. Kuravi, S.; Trahan, J.; Goswami, D.Y.; Rahman, M.M.; Stefanakos, E.K. Thermal energy storage technologies and systems for concentrating solar power plants. Prog. Energy Combust. Sci. 2013, 39, 285-319. [CrossRef]

3. Olasolo, P.; Juárez, M.C.; Morales, M.; D'Amico, S.; Liarte, I.; Castelló, M.C.J. Enhanced geothermal systems (EGS): A review. Renew. Sustain. Energy Rev. 2016, 56, 133-144. [CrossRef]

4. Chen, Y.-L.; Ni, J.; Shao, W.; Azzam, R. Experimental study on the influence of temperature on the mechanical properties of granite under uni-axial compression and fatigue loading. Int. J. Rock Mech. Min. Sci. 2012, 56, 62-66. [CrossRef]

5. Ge, Z.; Sun, Q. Acoustic emission (AE) characteristics of granite after heating and cooling cycles. Eng. Fract. Mech. 2018, 200, 418-429. [CrossRef]

6. Zhou, S.; Xia, C.; Hu, Y.; Zhou, Y.; Zhang, P. Damage modeling of basaltic rock subjected to cyclic temperature and uniaxial stress. Int. J. Rock Mech. Min. Sci. 2015, 77, 163-173. [CrossRef]

7. Hasnain, S. Review on sustainable thermal energy storage technologies, Part I: heat storage materials and techniques. Energy Convers. Manag. 1998, 39, 1127-1138. [CrossRef]

8. Li, B.; Ju, F.; Xiao, M.; Ning, P. Mechanical stability of granite as thermal energy storage material: An experimental investigation. Eng. Fract. Mech. 2019, 211, 61-69. [CrossRef]

9. Tiskatine, R.; Eddemani, A.; Gourdo, L.; Abnay, B.; Ihlal, A.; Aharoune, A.; Bouirden, L. Experimental evaluation of thermo-mechanical performances of candidate rocks for use in high temperature thermal storage. Appl. Energy 2016, 171, 243-255. [CrossRef]

10. Becattini, V.; Motmans, T.; Zappone, A.; Madonna, C.; Haselbacher, A.; Steinfeld, A. Experimental investigation of the thermal and mechanical stability of rocks for high-temperature thermal-energy storage. Appl. Energy 2017, 203, 373-389. [CrossRef]

11. Rong, G.; Peng, J.; Cai, M.; Yao, M.; Zhou, C.-B.; Sha, S. Experimental investigation of thermal cycling effect on physical and mechanical properties of bedrocks in geothermal fields. Appl. Therm. Eng. 2018, 141, 174-185. [CrossRef]

12. Peng, J.; Rong, G.; Tang, Z.; Sha, S. Microscopic characterization of microcrack development in marble after cyclic treatment with high temperature. Bull. Int. Assoc. Eng. Geol. 2019, 78, 5965-5976. [CrossRef]

13. Jin, P.; Hu, Y.; Shao, J.; Zhao, G.; Zhu, X.; Li, C. Influence of different thermal cycling treatments on the physical, mechanical and transport properties of granite. Geothermics 2019, 78, 118-128. [CrossRef]

14. Freire-Lista, D.M.; Fort, R.; Varas-Muriel, M.J. Thermal shock-induced microcracking in building granite. Eng. Geol. 2016, 203, 83-93. [CrossRef]

15. Battaglia, S.; Franzini, M.; Mango, F. High-sensitivity apparatus for measuring linear thermal expansion: Preliminary results on the response of marbles to thermal cycles. Il Nuovo Cimento C 1993, 16, 453-461. [CrossRef]

16. Lin, W. Permanent strain of thermal expansion and thermally induced microcracking in Inada granite. J. Geophys. Res. Space Phys. 2002, 107, ECV 3-1-ECV 3-16. [CrossRef]

17. Feng, G.; Kang, Y.; Meng, T.; Hu, Y.-Q.; Li, X.-H. The Influence of Temperature on Mode I Fracture Toughness and Fracture Characteristics of Sandstone. Rock Mech. Rock Eng. 2017, 50, 2007-2019. [CrossRef]

18. Fang, R. The Study on the Marble Macroscopic and Mesoscopic Mechanical Deformation Characteristics under the Periodical Change of Temperature; Hohai University: Nanjing, China, 2006.

19. Liu, Q.; Huang, S.; Kang, Y.; Liu, X. A prediction model for UCS of deteriorated rocks due to freeze-thaw. Cold Reg. Sci. Technol. 2015, 120, 96-107. [CrossRef]

20. Bayram, F. Predicting mechanical strength loss of natural stones after freeze-thaw in cold regions. Cold Reg. Sci. Technol. 2012, 83, 98-102. [CrossRef]

21. Tan, X.; Chen, W.; Yang, J.; Cao, J. Laboratory investigations on the mechanical properties degradation of granite under freeze-thaw cycles. Cold Reg. Sci. Technol. 2011, 68, 130-138. [CrossRef]

22. Gräf, V.; Jamek, M.; Rohatsch, A.; Tschegg, E. Effects of thermal-heating cycle treatment on thermal expansion behavior of different building stones. Int. J. Rock Mech. Min. Sci. 2013, 64, 228-235. [CrossRef] 
23. Momeni, A.A.; Karakus, M.; Khanlari, G.R.; Heidari, M. Effects of cyclic loading on the mechanical properties of a granite. Int. J. Rock Mech. Min. Sci. 2015, 77, 89-96. [CrossRef]

24. Ge, X.; Jiang, Y.; Lu, Y.; Ren, J. Testing study on fatigue deformation law of rock under cyclic loading. Chin. J. Rock Mech. Eng. 2003, 10, 1581-1585. (In Chinese)

25. Ge, X.; Lu, Y. Researches on rock fatigue failure and irreversible deformation under cycle loading. Chin. J. Geotech. Eng. 1992, 3, 56-60. (In Chinese)

26. Li, N.; Zhang, P.; Chen, Y.; Swoboda, G. Fatigue properties of cracked, saturated and frozen sandstone samples under cyclic loading. Int. J. Rock Mech. Min. Sci. 2003, 40, 145-150. [CrossRef]

27. Fan, J.; Chen, J.; Jiang, D.; Ren, S.; Wu, J. Fatigue properties of rock salt subjected to interval cyclic pressure. Int. J. Fatigue 2016, 90, 109-115. [CrossRef]

28. Fan, J.; Jiang, D.; Chen, J.; Liu, W.; Ngaha, W.T.; Chen, J. Fatigue performance of ordinary concrete under discontinuous cyclic loading. Constr. Build. Mater. 2018, 166, 974-981. [CrossRef]

29. Jiang, D.; Fan, J.; Chen, J.; Li, L.; Cui, Y. A mechanism of fatigue in salt under discontinuous cycle loading. Int. J. Rock Mech. Min. Sci. 2016, 86, 255-260. [CrossRef]

30. Fan, J.; Chen, J.; Jiang, D.; Chemenda, A.; Chen, J.; Ambre, J. Discontinuous cyclic loading tests of salt with acoustic emission monitoring. Int. J. Fatigue 2017, 94, 140-144. [CrossRef]

31. Chen, Y.; Watanabe, K.; Kusuda, H.; Kusaka, E.; Mabuchi, M. Crack growth in Westerly granite during a cyclic loading test. Eng. Geol. 2011, 117, 189-197. [CrossRef]

32. Liu, X.; Ning, J.; Tan, Y.; Gu, Q. Damage constitutive model based on energy dissipation for intact rock subjected to cyclic loading. Int. J. Rock Mech. Min. Sci. 2016, 85, 27-32. [CrossRef]

33. Li, T.; Pei, X.; Wang, D.; Huang, R.; Tang, H. Nonlinear behavior and damage model for fractured rock under cyclic loading based on energy dissipation principle. Eng. Fract. Mech. 2019, 206, 330-341. [CrossRef]

34. He, M.; Li, N.; Zhu, C.; Chen, Y.; Wu, H. Experimental investigation and damage modeling of salt rock subjected to fatigue loading. Int. J. Rock Mech. Min. Sci. 2019, 114, 17-23. [CrossRef]

35. Xiao, J.-Q.; Ding, D.-X.; Jiang, F.-L.; Xu, G. Fatigue damage variable and evolution of rock subjected to cyclic loading. Int. J. Rock Mech. Min. Sci. 2010, 47, 461-468. [CrossRef]

36. Xiao, J.-Q.; Ding, D.-X.; Xu, G.; Jiang, F.-L. Inverted S-shaped model for nonlinear fatigue damage of rock. Int. J. Rock Mech. Min. Sci. 2009, 46, 643-648. [CrossRef]

37. Ulusay, R.; Hudson, J.A. The complete ISRM suggested methods for rock characterization, testing and monitoring: 1974-2006. ISRM Commission on Testing Methods. Environ. Eng. Geosci. 2007, 15, 47-48.

38. Zhao, G.K.; Hu, Y.Q.; Jin, P.H.; Hu, Y.F.; Li, C. Experimental study on mechanical properties of granite subjected to cyclic loads under real time high temperature. Chin. J. Rock Mech. Eng. 2019, 38, 927-937. (In Chinese)

39. Zhao, Y.S.; Wan, Z.J.; Feng, Z.J.; Xu, Z.H.; Liang, W.G. Evolution of mechanical properties of granite at high temperature and high pressure. Géoméch. Geophys. Geo-Energy Geo-Resour. 2017, 3, 199-210. [CrossRef]

40. Wang, Z.; Li, S.; Qiao, L.; Zhao, J. Fatigue Behavior of Granite Subjected to Cyclic Loading Under Triaxial Compression Condition. Rock Mech. Rock Eng. 2013, 46, 1603-1615. [CrossRef]

41. Xie, H.; Peng, R.; Ju, Y. On energy analysis of rock failure. Chin. J. Rock Mech. Eng. 2005, 15, $2603-2608$. (In Chinese)

42. Xie, H.; Ju, Y.; Li, L. Criteria for strength and structural failure of rocks based on energy dissipation and energy release principles. Chin. J. Rock Mech. Eng. 2005, 17, 3003-3010. (In Chinese)

43. Liang, W.; Zhang, C.; Gao, H.; Yang, X.; Xu, S.; Zhao, Y. Experiments on mechanical properties of salt rocks under cyclic loading. J. Rock Mech. Geotech. Eng. 2012, 4, 54-61. [CrossRef]

44. Gatelier, N.; Pellet, F.L.; Loret, B. Mechanical damage of an anisotropic porous rock in cyclic triaxial tests. Int. J. Rock Mech. Min. Sci. 2002, 39, 335-354. [CrossRef]

45. Zhang, W.; Sun, Q.; Hao, S.; Geng, J.; Lv, C. Experimental study on the variation of physical and mechanical properties of rock after high temperature treatment. Appl. Therm. Eng. 2016, 98, 1297-1304. [CrossRef]

46. Dwivedi, R.D.; Goel, R.; Prasad, V.; Sinha, A. Thermo-mechanical properties of Indian and other granites. Int. J. Rock Mech. Min. Sci. 2008, 45, 303-315. [CrossRef] 
47. Vázquez, P.; Shushakova, V.; Gomez-Heras, M. Influence of mineralogy on granite decay induced by temperature increase: Experimental observations and stress simulation. Eng. Geol. 2015, 189, 58-67. [CrossRef]

48. Cerfontaine, B.; Collin, F. Cyclic and Fatigue Behaviour of Rock Materials: Review, Interpretation and Research Perspectives. Rock Mech. Rock Eng. 2017, 51, 391-414. [CrossRef]

49. Xi, D.; Liu, X.; Zhang, C. Strain response of cyclic hardening under fatigue loading on saturated rock. Chin. J. Rock Mech. Eng. 2003, 11, 1807-1810. (In Chinese)

50. Eberhardt, E.; Stead, D.; Stimpson, B. Quantifying progressive pre-peak brittle fracture damage in rock during uniaxial compression. Int. J. Rock Mech. Min. Sci. 1999, 36, 361-380. [CrossRef]

51. Bagde, M.; Petroš, V. Fatigue properties of intact sandstone samples subjected to dynamic uniaxial cyclical loading. Int. J. Rock Mech. Min. Sci. 2005, 42, 237-250. [CrossRef]

52. Bagde, M.N.; Petroš, V. Fatigue and dynamic energy behaviour of rock subjected to cyclical loading. Int. J. Rock Mech. Min. Sci. 2009, 46, 200-209. [CrossRef]

53. Munoz, H.; Taheri, A. Local Damage and Progressive Localisation in Porous Sandstone During Cyclic Loading. Rock Mech. Rock Eng. 2017, 50, 3253-3259. [CrossRef]

54. Dexing, L.; Enyuan, W.; Xiangguo, K.; Haishan, J.; Dongming, W.; Muhammad, A. Damage precursor of construction rocks under uniaxial cyclic loading tests analyzed by acoustic emission. Constr. Build. Mater. 2019, 206, 169-178. [CrossRef]

(C) 2020 by the authors. Licensee MDPI, Basel, Switzerland. This article is an open access article distributed under the terms and conditions of the Creative Commons Attribution (CC BY) license (http://creativecommons.org/licenses/by/4.0/). 